\title{
Pivôs utilizados nas brincadeiras de faz-de-conta de crianças brasileiras de cinco grupos culturais
}

\author{
Yumi Gosso \\ Maria de Lima Salum e Morais \\ Emma Otta \\ Universidade de São Paulo
}

\begin{abstract}
Resumo
O presente estudo comparou os pivôs utilizados nas transformações simbólicas de brincadeiras imaginativas de crianças de cinco grupos culturais brasileiros (41 meninas e 35 meninos, de quatro a seis anos de idade): de uma pequena comunidade praiana, de uma aldeia indígena e de três grupos de níveis socioeconômicos diferentes (alto, baixo e misto) de uma metrópole. Os pivôs foram classificados como elementos naturais, utensílios e brinquedos. Constatou-se que: (i) a escolha de pivôs relacionou-se com os objetos disponíveis: as crianças indígenas e da comunidade praiana usaram mais elementos naturais; as indígenas, mais utensílios e as da metrópole, mais brinquedos manufaturados; (ii) objetos pouco estruturados prestaram-se a um grande número de transformações simbólicas; (iii) meninas usaram mais reproduções de seres vivos e meninos, de veículos e armas. Em suma, os resultados indicam que as crianças, através dos pivôs, refletem nas brincadeiras sua individualidade e os valores de sua cultura.
\end{abstract}

Palavras-chave: brincadeira de faz-de-conta; brinquedos; diferenças culturais; diferenças de gênero; pivôs

\begin{abstract}
Pivots used in make-believe play by Brazilian children from five different cultural groups. In the present study, the pivots used for symbolic transformations in imaginative play by children from 5 cultural groups were compared. The participants were 76 children (41 girls and 35 boys, four to six years old) from five Brazilian cultural groups: a small seashore community, a village of Brazilian Indians, and three urban groups of different socioeconomic status (SES) from a metropolis (low SES, high SES, and mixed SES). The pivots were classified as natural elements, utensils, and toys. The results showed that: (i) the choice of pivots was associated with the available objects: Indian and seashore children used more natural elements; Indian children used more utensils and urban children, more toys; (ii) objects that were low structured suited a large variety of symbolic transformations; (iii) girls used more models of living beings, and boys, models of vehicles and weapons. In brief, the results indicate that the children, through the pivots, express their individuality and the values of their culture in their play.
\end{abstract}

Keywords: make-believe play; toys; cultural differences; gender differences; pivots

$\mathrm{H}$ á uma íntima relação entre os brinquedos que são disponibilizados para as crianças e os valores e normas culturais que se pretendem transmitir. Através dos adultos, sejam pais ou educadores, os grupos sociais, de acordo com seus princípios, propiciam às crianças os brinquedos que acreditam serem adequados ao seu desenvolvimento. Dessa forma, dentro da perspectiva de variações culturais, encontram-se sociedades que, valorizando o desenvolvimento cognitivo e o pensamento simbólico e lógico-abstrato, oferecem predominantemente às crianças brinquedos que têm a função de estimular suas habilidades cognitivas, simbólicas e lingüísticas. Em contraposição, há grupos culturais que, ado- tando valores de cooperação e enfatizando o raciocínio prático, incentivam mais brincadeiras que exercitam habilidades físicas, práticas e jogos de cooperação (Gosso, Otta, Morais, Ribeiro, \& Bussab, 2005; Morais, 2004).

Dentro desses grupos encontram-se também diferenças de gênero. Inúmeros trabalhos (e.g., Harris, 1998; Le ManerIdrissi, 1996; Maccoby, 1986) constataram que, desde cedo, há uma tipificação de gênero na escolha de brinquedos oferecidos à criança. Assim, bonecas são consideradas brinquedos de meninas, enquanto veículos, armas e miniaturas de heróis, brinquedos de meninos. Essa oferta de brinquedos ou permissão diferencial de seu uso faz parte de sistemas 
simbólicos e conceituais que são resultado de uma elaboração coletiva que compõe e particulariza as culturas (Nicolopoulou \& Weintraub, 1998).

Entendemos cultura como o "espaço real das relações dos homens entre si e com o seu mundo, como processo ativo, permanente e natural” (Oliveira, 1982, p. 106) e como os "conjuntos de ações e frutos de ações humanas que, transmitidos de geração em geração, constituem a identidade de um grupo humano e, ao mesmo tempo, o meio em que e pelo qual se constitui a identidade de seus membros" (Carvalho \& Pontes, 2003, p. 17).

A cultura infantil tem uma organização peculiar que não é apenas influenciada pela cultura em geral na qual está inserida, mas que também a influencia (Carvalho \& Rubiano, 2004; Friedmann, 1992; Oliveira, 1982). O papel ativo da criança possibilita que a cultura de sua geração vá além das anteriores, uma vez que as mensagens transmitidas pelos adultos são assimiladas pela criança de novas maneiras (De Conti \& Sperb, 2001). Portanto, "a relação entre desenvolvimento infantil e cultura passa inevitavelmente pela brincadeira" (Bichara, 2002, p. 146).

Quando consideramos os brinquedos em seu contexto social, não podemos pensá-los como objetos vazios de sentido, nem podemos encarar a criança que brinca como existindo fora de sua cultura. Os brinquedos são escolhidos não só para entreter as crianças, nem apenas para satisfazer suas necessidades físicas e socioemocionais, mas, também, por serem símbolos sociais que fazem referências específicas a atitudes e práticas culturais.

Segundo Sutton-Smith (1986) e De Conti e Sperb (2001), há um aspecto paradoxal na relação entre brinquedos e cultura: por um lado, os brinquedos são símbolos que comunicam significados explícitos para a criança; por outro, são as ferramentas utilizadas por ela para expressar sua imaginação de forma autônoma e seu crescimento socioemocional. Os brinquedos assumem um papel socializador importante, adquirindo, entre outras propriedades, as de sinalizar preocupações correntes e de indicar emblemas da identidade de gênero.

Brougère (1995) afirma que a socialização pressupõe a apropriação da cultura e o mecanismo pelo qual a criança dispõe de elementos da cultura passa, entre outras coisas, pela confrontação com imagens e com representações. Cada cultura tem imagens consideradas expressivas e é com elas que a criança se manifesta. Por essa razão, a brincadeira de faz-de-conta, em especial, propicia a expressão peculiar de significados culturais individuais e coletivos, na medida em que é uma manifestação aberta da projeção de conteúdos socioculturais absorvidos pelas crianças. Através do faz-deconta, as crianças mostram a forma como percebem os valores, opiniões e as ações características de sua cultura. Ao brincar de faz-de-conta, a criança está mudando o significado das coisas e deve fazê-lo através de códigos e significados socialmente adquiridos; ao mesmo tempo, está criando um novo significado, que pode passar a ser compartilhado no grupo de brinquedo, tornando-se um novo elemento da cultura e da história do grupo (Morais \& Carvalho, 1994).
Sutton-Smith (1986) acredita na brincadeira livre como forma de desenvolvimento e expressão da criatividade infantil, argumentando que a imaginação lúdica domina os objetos, e não o contrário. Na criação de novos sentidos para as coisas, durante a brincadeira imaginativa, a criança freqüentemente utiliza objetos intermediários, ou pivôs. Neste trabalho, aplicamos o termo pivô no sentido empregado por Vygotsky (1984). Esse autor considera que a criança, ao brincar, passa a agir independentemente do objeto e que, portanto, os objetos perdem sua força determinadora. A criança, ao simular uma conjuntura, age num campo hipotético, dirigindo seu comportamento mais pelo significado da situação do que por sua percepção imediata. Vygotsky considera também que a criança, não conseguindo ainda separar o pensamento do objeto real, valer-se-ia do brinquedo como elemento que propiciaria um estágio na direção dessa separação. Por essa razão, ela necessitaria de pivôs, ou seja, de objetos que permitem a separação do significado da coisa em si. Dessa forma, a criança usa a boneca como pivô, ao tratá-la como um ser humano com vida ou um graveto como pivô, ao tratá-lo como espada, batom ou vara de condão. Pivôs são, portanto, os objetos que sofrem transformações de significado durante a brincadeira simbólica.

Portanto, no estudo das brincadeiras imaginativas, devese considerar que: (1) os ambientes em que ocorrem as brincadeiras são estruturados fisicamente de acordo com crenças, expectativas e valores das pessoas que os organizam, constituindo um sistema de significado cultural próprio; (2) a criança tem um papel ativo na produção de suas brincadeiras, construindo sua versão pessoal dos eventos sociais; e (3) a criança externaliza esta compreensão através da ação.

A maior parte dos estudos sobre desenvolvimento foi realizada com crianças do mundo ocidental, vivendo em zona urbana, em sua maioria nos Estados Unidos e na Europa. Além disso, a maioria dos estudiosos do desenvolvimento tem privilegiado o estudo de processos que ocorrem em ambientes artificiais, na presença de adultos estranhos (Bruner, 1990). A nosso ver, informações relevantes podem ser obtidas com crianças de outros ambientes culturais, incluindo as minorias, como os povos indígenas, e estudando-as em seu ambiente natural de inserção e em contextos em que os pesquisadores podem captar as sutilezas de sua compreensão social (Dunn, 1988). A extensão geográfica do Brasil, com sua grande diversidade de raças e culturas, favorece pesquisas comparativas não só entre diferentes regiões do país, como também entre grupos culturais distintos dentro de uma mesma região. O Brasil tem ainda muitas comunidades que vivem isoladas, como alguns grupos indígenas e comunidades rurais, que preservam valores tradicionais e, ao mesmo tempo, grandes centros urbanos que incorporam toda a sorte de inovações tecnológicas e cujos valores estão em constante transformação.

O presente estudo se propõe a averiguar como ocorrem as apropriações de objetos nas transformações simbólicas executadas no contexto da brincadeira de faz-de-conta como essa ocorre espontaneamente em ambientes naturais, em função de diferenças culturais e de gênero. Comparamos os pivôs 
utilizados nas transformações simbólicas de brincadeiras imaginativas de crianças de cinco grupos culturais brasileiros: de uma pequena comunidade praiana (Ubatuba, SP), de uma aldeia indígena (Paranowaona, PA) e de três grupos pertencentes a níveis socioeconômicos diferentes (alto, baixo e misto) da cidade de São Paulo.

Mais especificamente, o trabalho teve como objetivos: i) classificar os pivôs em elementos naturais, utensílios e brinquedos manufaturados; ii) categorizar os brinquedos em cinco agrupamentos: (1) brinquedos pouco estruturados e miniaturas de (2) seres vivos, de (3) seres fantásticos, de (4) utensílios domésticos e de (5) veículos e armas; iii) analisar os objetos em que os diversos pivôs foram transformados simbolicamente no conjunto das cinco amostras.

\section{Método}

\section{Participantes}

Foram observadas 76 crianças, 41 meninas e 35 meninos, de quatro a seis anos de idade, de cinco diferentes grupos sociais: 12 crianças indígenas de Paranowaona (seis meninas e seis meninos); 13 de Ubatuba (sete meninas e seis meninos); 20 de nível sócio-econômico (NSE) baixo da cidade de São Paulo (10 meninas e 10 meninos); 20 de NSE alto (sete meninos e 13 meninas); e 11 de NSE misto (seis meninos e cinco meninas) da cidade de São Paulo.

\section{Amostra indígena Parakanã}

Todas as crianças Parakanã do presente estudo eram oriundas da aldeia Paranowaona, uma das cinco aldeias da reserva indígena Parakanã, localizada na região sudeste do Estado do Pará, entre os municípios de Novo Repartimento e Itupiranga. Na área da reserva, de 351.697 ha, viviam 502 índios (censo de 2000), divididos em cinco aldeias. Durante a coleta de dados, a aldeia Paranowaona possuía 86 habitantes. Os índios Parakanã foram contatados no início da década de 1970 e estão sendo assistidos pelo Programa Parakanã desde 1987. Esse Programa, fruto do convênio entre FUNAI e Eletronorte, oferece assistência à saúde, educação, apoio à produção e defesa do território.

Esses índios vivem da caça, da coleta e do cultivo de alguns produtos como o milho, o arroz, a banana, o feijão e a mandioca, sendo que somente esse último é utilizado exclusivamente para consumo, enquanto os demais são destinados não só para o consumo, mas também para venda nos pequenos comércios das proximidades. $\mathrm{O}$ dinheiro arrecadado com essa venda é dividido entre as famílias que cultivaram e auxiliaram na colheita.

Não há acesso à televisão, nem a telefone nas aldeias. A reserva é composta de mata nativa com muitos animais típicos da região amazônica, como jacarés, cotias, pacas, porcos do mato, jabutis, tatus, capivaras, veados e diversas espécies de aves e peixes. A partir de três anos de idade, as crianças brincam em grupo sem supervisão de adultos. A primeira autora foi responsável pelas observações que ocorreram durante as atividades livres em vários pontos da aldeia. A pre- sença da observadora na aldeia foi condicionada a que ela desse aulas para crianças e adultos na língua Parakanã na escola local.

\section{Amostra de Ubatuba}

As crianças de Ubatuba viviam em Itamambuca, uma das 92 praias de Ubatuba, município do litoral norte do Estado de São Paulo que contava com 66.861 habitantes (censo de 2000), vivendo numa área de $682 \mathrm{~km}^{2}$. Nos séculos XVII e XVIII, Ubatuba foi um porto de escoamento de minerais e uma área de engenhos de cana-de-açúcar. Atualmente, a maior parte da sua economia baseia-se no turismo. A região de Itamambuca tem uma baixa densidade populacional e abundantes recursos naturais, como mata nativa, rios, cachoeiras, além da praia e do mar. As crianças de nossa amostra viviam em áreas pobres perto da escola e nos bairros próximos. A maior parte de seus pais eram caseiros, jardineiros, artesãos e trabalhadores da construção civil. A escola pública freqüentada pelas crianças tinha boas instalações, um campo de futebol e dois pátios externos. A segunda autora e um assistente de pesquisa foram responsáveis pelas observações durante os períodos de atividade livre, em que as crianças podiam circular pelo espaço externo da escola.

\section{Amostra de NSE baixo da cidade de São Paulo}

As crianças de nível socioeconômico baixo freqüentavam uma escola pública localizada na zona oeste da cidade de São Paulo. Algumas delas viviam em uma favela localizada nas proximidades da escola. Outras habitavam em bairros densamente povoados das cercanias, em casas pequenas com muitos moradores, iluminação e arejamento precários, com pequena área externa e escassa área verde. A maior parte de seus pais eram excluídos do mercado de trabalho formal, vivendo de ocupações eventuais na construção civil, de pequenas vendas ou trabalhando como empregados domésticos.

\section{Amostra de NSE alto}

As crianças de nível sócio-econômico alto freqüentavam uma escola particular localizada dentro de um condomínio fechado da zona oeste de São Paulo. A maioria das crianças era moradora do próprio condomínio, que contava com boa infra-estrutura de lazer. A escola possuía diversos equipamentos de playground, área de esportes, piscina, além de uma brinquedoteca com diversos brinquedos em miniatura, exceto miniaturas de armas. Os pais das crianças desta amostra eram profissionais autônomos, empresários e executivos.

\section{Amostra de NSE misto}

Este grupo de crianças freqüentava uma creche localizada no município de São Paulo que atendia os filhos de alunos e funcionários de uma universidade pública. Os pais enquadravam-se em diferentes setores da universidade. Havia entre eles trabalhadores em gráfica, almoxarifado, cozinha, alunos de pós-graduação, professores, escriturários, secretárias e pessoal de nível técnico. A segunda autora observou a amostra de NSE misto e assistentes de pesquisa treinados observaram as outras duas amostras. 


\section{Procedimento de coleta de dados}

Utilizou-se para coleta de dados o método de observação por sujeito focal (Altmann, 1974). Cada sessão de observação tinha cinco minutos de duração, sendo dividida em períodos de um minuto. O número médio de sessões foi seis. Registraram-se as brincadeiras de faz-de-conta. Segundo Garvey (1990) e Haight, Wang, Fung, Williams e Mintz (1999), a brincadeira de faz-de-conta é definida como uma subcategoria de brincadeira, na qual as ações, objetos, pessoas, lugares ou outras dimensões da realidade são transformadas ou tratadas de maneira não literal.

Além das duas primeiras autoras, seis assistentes de pesquisa treinados coletaram os dados. Após um período de treino usando transcrições, calculou-se a fidedignidade relativa aos códigos de comportamento. A fidedignidade foi computada para pares de pesquisadores com base em 30 minutos de registro selecionados ao acaso. Os índices Kappa entre os pares de juízes variaram de 0,81 a 0,97. As análises basearamse em registro escritos.

\section{Procedimento de análise}

Os tipos de objetos (também chamados de pivôs) sobre os quais as crianças operavam as transformações simbólicas foram classificados, da mesma forma que o fizeram Striano, Tomasello e Rochat (2001), em:

(1) Elementos naturais - Todos aqueles existentes na natureza, isto é, que não sofreram transformação por parte do homem. Exemplo: areia, argila, água, plantas e suas partes, pedra.

(2) Utensílios - Objetos que se prestavam a alguma utilidade na vida cotidiana dos adultos. Em geral, eram objetos transformados manual ou industrialmente. Exemplos: sucata ou fragmentos de materiais diversos (tecido, plástico, canudo, papel, papelão, prego, botão de fogão, telefone, pneus), recipientes e objetos feitos à mão (canoa, vestido, galinheiro).

(3) Brinquedos manufaturados - Objetos materialmente construídos com o objetivo precípuo de entreter as crianças. Suas formas de criação variam desde as artesanais até as inteiramente industrializadas (Oliveira, 1982). Exemplos: miniaturas de seres humanos, de personagens fantásticos, de animais e de outros objetos, peças geométricas, brinquedos de areia e equipamentos de playground.

Os índices de utilização de pivôs foram obtidos dividindo-se os escores brutos pelo tempo total de emprego de pivôs durante as brincadeiras de faz-de-conta.

\section{Resultados}

Foi efetuada uma Análise de Variância Multivariada 5 x 2 para verificar a influência do grupo cultural e do sexo das crianças sobre os pivôs utilizados em suas modificações simbólicas. A MANOVA revelou efeito global significativo de grupo cultural: lambda de Wilks $=0,440 ; F_{16,193}=3,719 ; p<$ 0,001 . Não houve efeito de sexo (lambda de Wilks $=0,924$; $\left.F_{4,63}=1,295 ; p=0,282\right)$, nem de interação entre grupo cultural e sexo (lambda de Wilks $=0,787 ; F_{16,193}=0,987 ; p=0,472$ ).
Análises univariadas subseqüentes revelaram efeito de grupo cultural sobre a utilização de elementos naturais $\left(F_{4,66}=\right.$ 4,688; $p<0,01)$, de utensílios $\left(F_{4,66}=7,964 ; p<0,001\right)$ e de brinquedos $\left(F_{4,66}=8,536 ; p<0,001\right)$.

A Figura 1 ilustra a freqüência do uso de elementos naturais, utensílios e brinquedos pelos cinco grupos. Através de comparações dois-a-dois pela prova de Tukey, verificou-se que: (i) as crianças praianas usaram mais elementos naturais do que as crianças de São Paulo de NSE misto $(p<0,05)$ e de NSE baixo ( $p<0,05)$; (ii) a utilização de utensílios foi maior por parte das crianças indígenas de Paranowaona do que por parte dos demais grupos: Ubatuba $(p<0,001)$, NSE baixo $(p<$ $0,001)$, NSE alto $(p<0,001)$ e NSE misto $(p<0,05)$ de São Paulo, respectivamente; (iii) as crianças de Paranowaona usaram menos brinquedos do que as de NSE baixo, misto e alto de São Paulo ( $p<0,001$ ); (iiii) as crianças praianas usaram significativamente menos brinquedos do que as de NSE alto e misto de São Paulo $(p<0,05)$.

Quanto aos brinquedos (Tabela 1), observou-se que o uso de miniaturas de seres vivos (e.g., bonecas, cachorros, cavalos) prevaleceu entre as meninas, havendo diferenças de gênero neste aspecto nas amostras de Paranowaona, NSE misto e NSE alto de São Paulo. Miniaturas de seres fantásticos foram encontradas apenas na amostra de NSE misto, prevalecendo entre os meninos. Miniaturas de veículos e armas foram utilizadas predominantemente por meninos de Ubatuba, NSE baixo e misto de São Paulo. Miniaturas de utensílios domésticos foram usadas principalmente pelas meninas de Ubatuba e de NSE baixo. Na amostra de NSE alto, os meninos empregaram utensílios domésticos com freqüência semelhante àquela verificada entre as meninas. Brinquedos pouco estruturados (blocos, equipamentos de playground) predominaram entre os meninos de NSE baixo de São Paulo.

A Tabela 2 mostra os pivôs (elementos naturais e utensílios) e os objetos em que foram simbolicamente transformados no conjunto das cinco amostras. Constatou-se que objetos pouco estruturados, como partes de plantas, areia e fragmentos se prestaram a grande variedade de transformações simbólicas. Os utensílios, principalmente os menos estruturados, como fragmentos, recipientes e peças, e os elementos naturais propiciaram simbolizações variadas. Por exemplo, areia, argila ou pedra foram transformadas em 27 elementos diferentes e fragmentos diversos ou sucata representaram 25 objetos.

\section{Discussão}

Na análise da escolha diferencial de objetos como pivôs para as transformações simbólicas, temos que considerar ao menos três aspectos da questão: 1) o número e a variedade de elementos lúdicos de que a criança dispõe, que são oferecidos pelos adultos de sua comunidade; 2) a escolha que a criança faz de alguns objetos em detrimento de outros; e 3) as representações que cria a partir de determinados pivôs. 


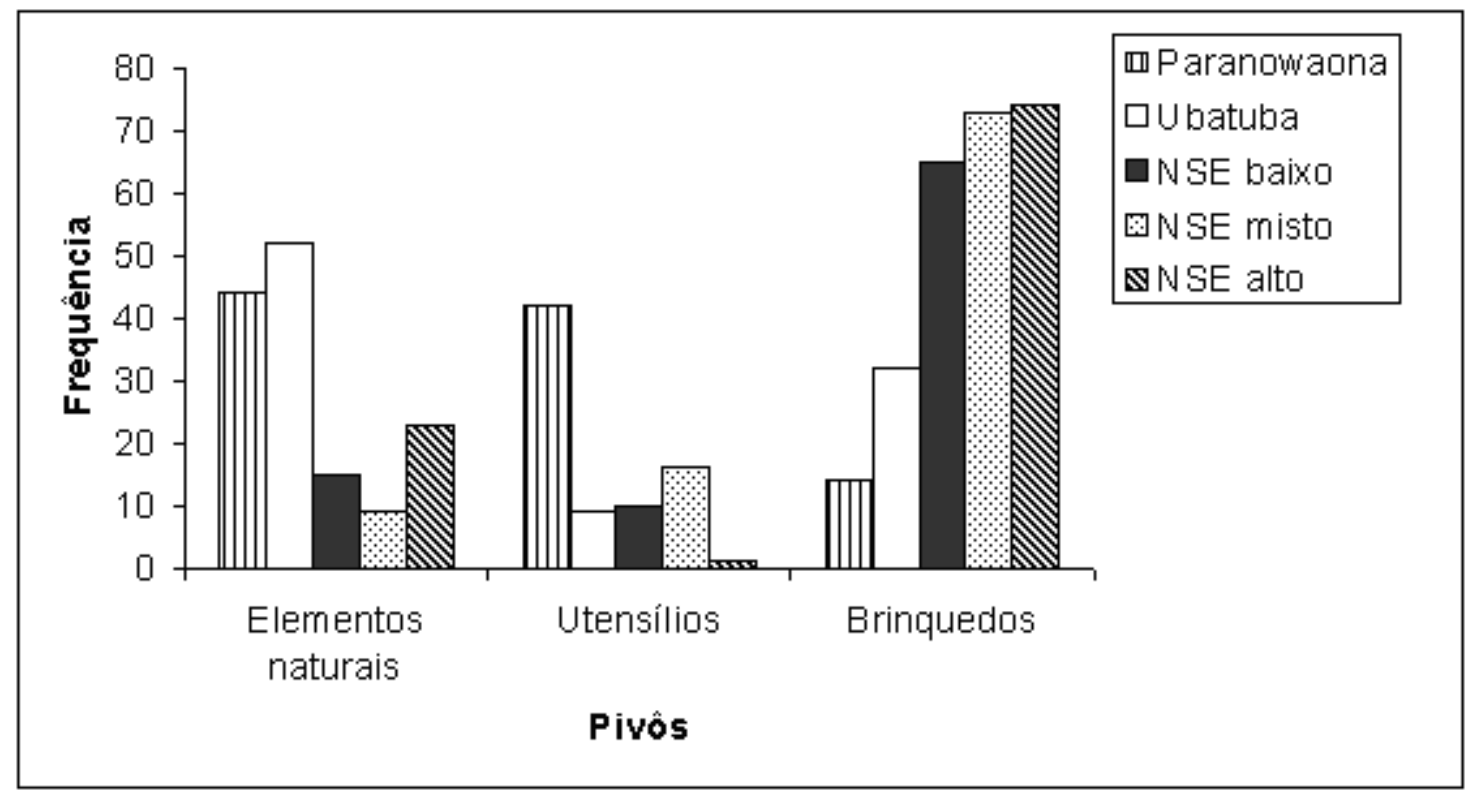

Figura 1. Freqüência do uso dos diversos pivôs pelas crianças dos cinco grupos culturais.

Tabela 1

Freqüência de utilização de brinquedos manufaturados como pivôs em função de sexo e grupo cultural

\begin{tabular}{lccccccccccc}
\hline & \multicolumn{2}{c}{ Paranowaona } & \multicolumn{2}{c}{ Ubatuba } & \multicolumn{2}{c}{ NSE baixo } & \multicolumn{2}{c}{ NSE misto } & \multicolumn{2}{c}{ NSE alto } \\
\cline { 2 - 13 } & M & F & M & F & M & F & M & F & M & F \\
\hline Mini seres vivos & - & 15,38 & - & 2,94 & 15,38 & 15,38 & 15,09 & 39,22 & 2,04 & 14,58 \\
Mini seres fantásticos & - & - & - & - & - & - & 47,17 & 7,84 & - & - \\
Mini veículos e armas & - & 2,56 & 26,03 & - & 10,26 & 1,28 & 11,32 & - & - & - \\
Mini utensílios domésticos & - & - & - & 26,47 & 5,13 & 21,79 & 1,89 & 3,92 & 55,1 & 47,22 \\
Brinquedos pouco estruturados & - & - & 3,7 & 2,94 & 61,54 & 20,51 & 7,55 & 9,86 & 16,33 & 10,41 \\
\hline
\end{tabular}

Nota: $\mathrm{M}=$ masculino; $\mathrm{F}$ = feminino

Tabela 2

Representações originadas dos diversos pivôs

\begin{tabular}{|c|c|}
\hline Pivô & Transformado em \\
\hline \multicolumn{2}{|l|}{ Elementos naturais } \\
\hline Partes da planta & $\begin{array}{l}\text { Bacia, dinheiro, carro, sabão, escovinha, bem possuído, lenha, prancha, comida, } \\
\text { veneno, bolo, trampolim, pasto, espanador, estojo de maquiagem }\end{array}$ \\
\hline Areia, argila, pedra & $\begin{array}{l}\text { Pênis, comida, tartaruga, suco, chuva, água, rio, bolo, casa, água, arroz, café, doce, } \\
\text { casa, abelha, barata, bebê, brigadeiro, castelo, cobra, comida, formiga, leite } \\
\text { condensado, macarrão, minhoca, pipoca, sal }\end{array}$ \\
\hline Tábua, pau & Prancha, pênis, batom, pincel \\
\hline Água & Leite, rio, refrigerante \\
\hline \multicolumn{2}{|l|}{ Utensílios } \\
\hline $\begin{array}{l}\text { Fragmentos (plástico, madeira, } \\
\text { tecido, papel, papelão, canudo) }\end{array}$ & $\begin{array}{l}\text { Rede, casa, boné, carro, esponja, telefone, colher, desodorante, avião, gangorra, } \\
\text { munição, revólver, bebê, flor, pulseira, embrulho, fôrma, pastel, porta, castelo, quarto, } \\
\text { parafuso, volante, garagem, apito }\end{array}$ \\
\hline $\begin{array}{l}\text { Recipientes (latas, vasilhas, } \\
\text { cestas e caixotes) }\end{array}$ & $\begin{array}{l}\text { Carro, cama, barco, casa de cachorro, panela, mamadeira, volante, forma, copo, } \\
\text { bandeja, louça, bateria, fôrma, avião, labirinto, saleiro, esmalte }\end{array}$ \\
\hline $\begin{array}{l}\text { Industrializados (carro de mão, } \\
\text { prego, botão de fogão, telefone, } \\
\text { pneu, canudo) }\end{array}$ & $\begin{array}{l}\text { Panela, carro, grampo, criança, mercearia, comida, telefone, mamadeira, arma, } \\
\text { restaurante, casa, porta, tesoura, castelo, poço }\end{array}$ \\
\hline $\begin{array}{l}\text { Objetos feitos à mão (canoa, } \\
\text { vestido, galinheiro) }\end{array}$ & Casa, água, uniforme \\
\hline
\end{tabular}


Embora tenhamos registrado os objetos disponíveis para a brincadeira nos cinco grupos culturais estudados, não tivemos controle sobre sua distribuição. Nas escolas de São Paulo, a oferta de brinquedos manufaturados era abundante, sendo esses os mais escolhidos entre as crianças das três amostras dessa cidade. No grupo de crianças praianas, a professora disponibilizava brinquedos apenas em alguns momentos. A freqüência com que as crianças ubatubanas utilizavam brinquedos manufaturados foi menor do que as de São Paulo e maior do que as de Paranowaona. Essas últimas dispunham de poucos brinquedos industrializados (apenas bonecas e carros) e de alguns brinquedos feitos a mão, como canoas e arcos e flechas.

Entre os índios prevaleceu o uso de utensílios como pivôs: caixas, sacos plásticos, pedaços de madeira e prego. Bichara (2002) também constatou entre os índios Xocó, que vivem no Estado de Sergipe, às margens do rio São Francisco, o uso freqüente de sucata, de utensílios domésticos e de trabalho como pivôs para simbolização. Smith (2004) também apresenta evidências de que os pivôs utilizados nas brincadeiras de crianças de outras sociedades não industrializadas são os materiais disponíveis, inclusive para o trabalho adulto.

Considerando que as crianças indígenas estão próximas dos pais e começam a trabalhar desde cedo, pode-se supor que elas tenham maior familiaridade com utensílios domésticos e instrumentos de trabalho. Além disso, os pais não colocam restrições ao uso desses objetos como o fazem os pais nas sociedades industrializadas. Constatamos, igualmente, que as crianças indígenas utilizaram elementos naturais como pivôs tanto quanto os utensílios. O uso de elementos da natureza foi igualmente freqüente entre as crianças ubatubanas.

Pelos dados obtidos, pode-se conjecturar que, no caso das crianças praianas, os elementos naturais substituíram parcialmente os brinquedos manufaturados e que, no caso das crianças de Paranowaona, tanto os elementos da natureza quanto os utensílios (sucata, instrumentos domésticos e de trabalho) fizeram as vezes dos brinquedos manufaturados utilizados pelas crianças paulistanas. Como não foi possível controlar a oferta de brinquedos, não podemos afirmar que as crianças ubatubanas e indígenas tiveram preferência por elementos naturais e/ou utensílios. Entretanto, é importante observar que, mesmo na ausência de brinquedos manufaturados - que, segundo McLoyd (1983) e Striano et al. (2001), favorecem a simbolização -, essas crianças brincaram de fazde-conta utilizando-se de quaisquer objetos disponíveis, mesmo que não tenham sido especificamente produzidos para essa finalidade.

Os brinquedos manufaturados prestam-se principalmente a transformações de propriedade, pois a maior parte deles são miniaturas do que pretendem representar (e.g., boneca por bebê, carro de plástico por carro de verdade). Nessa medida, embora, conforme McLoyd (1983) e Striano et al. (2001), os brinquedos facilitem a simbolização, eles também restringem o tipo e a quantidade de transformações simbólicas realizadas pelas crianças. Assim, uma locomotiva de brinquedo mais provavelmente evocará a representação de uma locomotiva real do que de outro objeto qualquer.

Constatou-se grande número e variedade de transformações simbólicas operadas em pivôs menos estruturados, como partes de plantas (principalmente folhas), areia, argila e pedras e fragmentos de utensílios e recipientes. McLoyd (1983) e Smith (1995) também observaram que brinquedos menos estruturados - como é o caso dos elementos naturais e dos utensílios - propiciavam maior variedade de substituições e, por conseguinte, estimulavam a criatividade. Sager e Sperb (1998) constataram que objetos menos estruturados (caixas, tábuas) favoreciam o desenvolvimento da brincadeira de fazde-conta e que, quando tais objetos eram transformados simbolicamente, podiam até mesmo passar a ter um valor afetivo maior do que os demais. Além do valor afetivo e da possibilidade de um número maior de simbolizações, Mello, Fachel e Sperb (1997) afirmam que a utilização de materiais sem especificidade lúdica favorece a construção de significados comuns, que devem ser negociados, uma vez que não existe para eles um fim determinado. Essa última afirmativa leva-nos a supor que as interações sociais - verbais e não-verbais também devem ser privilegiadas nas brincadeiras em que as crianças usam objetos menos estruturados, na medida em que elas precisam tornar claro para os companheiros o significado de determinado objeto num dado momento.

Constatamos, de maneira geral, que as meninas utilizaram mais miniaturas de seres vivos e de utensílios domésticos como pivôs do que os meninos. Segundo Kline (1995), ao redor dos cinco anos, as crianças preferem brinquedos denotativos dos papéis sociais de seu gênero. Para Liss (1981), a brincadeira de bonecas de meninas pode propiciar uma ocasião social mais caracterizada pela interação do que pela manipulação de objetos e ação. Bichara (2002) também constatou diferenças de gênero semelhantes nas brincadeiras das crianças Xocó.

A utilização de miniaturas de veículos e de armas pelos meninos é consistente com dados da literatura que indicam que esses preferem brincadeiras que explorem temas universais de disputa por dominância, de amizade e de solidariedade dentro de padrões de conflito interpessoal estilizados, como ataque, defesa, fuga e captura (Kline, 1995). A utilização de seres fantásticos por parte dos meninos de NSE misto corrobora essa afirmação.

Dois achados nos surpreenderam no presente estudo. O primeiro foi a utilização de miniaturas de seres fantásticos exclusivamente por parte das crianças de NSE misto. Uma explicação para esse resultado é o fato de que a creche onde estas crianças estudavam era a única que permitia que os alunos trouxessem brinquedos de casa (miniaturas de Pokemon, Digimon, etc.).

O segundo achado que nos surpreendeu foi o fato de os meninos de NSE alto brincarem com utensílios domésticos tanto quanto as meninas. Uma das possibilidades para explicar esse dado era a franca disponibilidade e abundância de brinquedos de miniatura de utensílios domésticos na escola em que ocorreu a observação. Outra hipótese é que o fato de 
as crianças da escola de NSE alto morarem em condomínio fechado e de serem altamente protegidas pode ter gerado uma aproximação maior com os trabalhos e afazeres domésticos. Além disso, pelo fato de os pais dessa camada social ausentarem-se freqüentemente de casa para trabalhar, é possível que falte às crianças modelos de identificação de trabalhos tipicamente masculinos de nossa sociedade. Ou ainda, pode-se supor que haja menor estereotipia de gênero entre as famílias de NSE alto observadas, apoiada pela escola, que tinha entre as atividades programadas aulas de cozinha experimental (culinária) para alunos de ambos os sexos. $\mathrm{Na}$ brinquedoteca, havia uma casa de tamanho compatível com as crianças, mobiliada com utensílios em miniatura. Pode-se conjecturar que as aulas de culinária tenham aumentado a atratividade dos utensílios domésticos tanto para meninas quanto para meninos. Crianças de NSE misto também dispunham de um canto na sala com objetos que reproduziam uma casa em miniatura e as ubatubanas, de uma caixa cheia de miniaturas de utensílios domésticos. Verifica-se, entretanto, que a mera disponibilidade desses objetos não propiciou praticamente o uso de miniaturas de utensílios domésticos entre os meninos dessas amostras. Acreditamos, portanto, que atividades programadas pela escola, como as aulas de culinária, tiveram um papel essencial na redução do uso de brinquedos estereotípicos de gênero.

É possível ainda conjecturar-se que pais e educadores das crianças de NSE alto tivessem atitudes menos conservadoras e menos estereotipadas em relação aos papéis masculino e feminino. A favor dessa hipótese, citamos o estudo de Carvalho, Beraldo, Santos e Ortega (1993), que constataram que crianças de classe alta de São Paulo, quando comparadas a crianças de classe baixa da mesma cidade, tendiam a considerar que uma mesma brincadeira era igualmente adequada para meninos e meninas. No entanto, para se averiguar a procedência dessas hipóteses, são necessários estudos adicionais que analisem sistematicamente o efeito da disponibilidade de brinquedos, da atitude da escola e da atitude dos pais.

Por nos termos baseado numa metodologia de observação naturalística do comportamento - que tem a grande vantagem de retratar a atividade espontânea da criança -, não foram possíveis, evidentemente, controles que propiciariam conclusões mais contundentes. Entretanto, este trabalho indica um caminho para estudos posteriores, cujo delineamento permita o controle de algumas variáveis que podem atuar na escolha de brinquedos pela criança, como, entre outras: espaço e tempo reservado para a brincadeira; oferta seletiva de diferentes pivôs (com variações na seqüência de apresentação dos materiais); modalidade de interferência do adulto que monitora as atividades - que pode ser, mediante combinação prévia, diferencialmente diretivo, aprovador ou reprovador das escolhas feitas pelas crianças; atitudes dos pais e educadores em relação a determinados tipos de pivô.

Contudo, indubitavelmente, pode-se concluir que as escolhas de pivôs em que se baseiam as atividades lúdicas infantis refletem, assim como as próprias brincadeiras, o fazer humano, e, através delas, a criança expressa, não só sua individualidade, mas também, a ideologia de sua cultura.

O brinquedo - eis aí algo pan-humano, que está tão arraigado na nossa natureza e nas nossas culturas, em todos os lugares e todos os tempos, que talvez algum dia venhamos a fazer a nossa história através dos brinquedos (Houaiss, 1982, p. 38).

\section{Agradecimentos}

Ao CNPq pelo apoio financeiro, a João Carlos Otta, Luis Fernando de Oliveira Saraiva, Izabel Almeida, Daniele Carli Licciardi, Márcio Berber Diz Amadeu, Caroline Toshie Hara, e Fernanda Cazelli Buckeridge pelo auxílio na coleta de dados e a Gisele Zago pela colaboração na análise dos dados e aos revisores por suas importantes contribuições.

\section{Referências}

Altmann, J. (1974). Observational study of behavior sampling methods. Behavior, 49, 227-265.

Bichara, I. D. (2002). Crescer como índio às margens do Velho Chico: um desafio para as crianças Xocó. In E. R. Lordelo, A. M. A. Carvalho, \& S. H. Koller (Orgs.), Infância brasileira e contextos de desenvolvimento (pp. 137-163). São Paulo: Casa do Psicólogo.

Brougère, G. (1995). Brinquedo e cultura. São Paulo: Cortez.

Bruner, J. S. (1990). Culture and human development: a new look. Human Development, 33, 344-355.

Carvalho, A. M. A., Beraldo, K., Santos, F., \& Ortega, R. (1993). Brincadeiras de menino, brincadeiras de menina. Psicologia: Ciência e Profissão, 13(1,2,3,4), 30-33.

Carvalho, A. M. A., \& Pontes, F. A. R. (2003). Brincadeira é cultura. In A. M. A. Carvalho, C. M. C. Magalhães, F. A. R. Pontes, \& I. D. Bichara (Orgs.), Brincadeira e cultura: viajando pelo Brasil que brinca (pp. 15-30). Vol. I. São Paulo: Casa do Psicólogo.

Carvalho, A. M. A. \& Rubiano, M. R. B. (2004). Vínculo e compartilhamento na brincadeira de crianças. In M. C. Rossetti-Ferreira, K. S. Amorim, A. P. S. Silva, \& A. M. A. Carvalho (Orgs.), Rede de significações e o estudo do desenvolvimento humano (pp.171-187). Porto Alegre: Artmed.

De Conti, L., \& Sperb, T. M. (2001). O brinquedo de pré-escolares: um espaço de ressignificação cultural. Psicologia: Teoria e Pesquisa, 17, 59-67.

Dunn, J. (1988). The beginnings of social understanding. Cambridge: Harvard University Press.

Friedmann, A. (1992). A evolução do brincar. In A. Friedman (Org.), O direito de brincar: a brinquedoteca (pp. 23-31). São Paulo: Scritta/ ABRINQ.

Garvey, C. (1990). Play. Cambridge: Harvard University Press.

Gosso, Y., Otta, E., Morais, M. L. S., Ribeiro, F. J. L., \& Bussab, V. S. R. (2005). Play in hunter-gatherer society. In A. D. Pellegrini \& P. K. Smith (Orgs.), The nature of play: great apes and humans (pp. 213253). Nova York: Guilford.

Haight, W. L., Wang, X., Fung, H. H., Williams, K., \& Mintz, J. (1999). Universal, developmental, and variable aspects of young children's play: a cross-cultural comparison of pretending at home. Child Development, 70, 1477-1488.

Harris, J. R. (1998). Diga-me com quem anda... Rio de Janeiro: Objetiva.

Houaiss, A. (1982). Brinquedos brasileiros. In P. S. Oliveira (Org.), Brinquedos artesanais e expressividade cultural (pp. 35-39). São Paulo: SESC-CELAZER. 
Kline, S. (1995). The promotion and marketing of toys: time to rethink the paradox? In A. D. Pellegrini (Org.), The future of play theory: a multidisciplinary inquiry into the contributions of Brian Sutton-Smith (pp. 165-185). Nova York: State University of New York Press.

Le Maner-Idrissi, G. (1996). An internal gender system at 24 months. European Journal of Psychological Education, 11, 301-312.

Liss, M. B. (1981). Patterns of toy play: an analysis of sex differences. Sex Roles, 7, 1143-1150.

Maccoby, E. E. (1988). Gender as a social category. Developmental Psychology, 24, 755-765.

McLoyd, V. C. (1983). The effects of the structure of play objects on the pretend play of low-income preschool children. Child Development, 54, 626-635.

Mello, C. O., Fachel, J., \& Sperb, T. M. (1997). A interação social na brincadeira de faz-de-conta: uma análise da dimensão metacomunicativa. Psicologia: Teoria e Pesquisa, 13, 119-130.

Morais, M. L. S. (2004). Conflitos e(m) brincadeiras infantis: diferenças culturais e de gênero. Tese de doutorado não-publicada, Instituto de Psicologia da Universidade de São Paulo, São Paulo.

Morais, M. L. S., \& Carvalho, A. M. A. (1994). Faz-de-conta: temas, papéis e regras na brincadeira de crianças de quatro anos. Boletim de Psicologia, 100/101, 21-30.
Nicolopoulou, A., \& Weintraub, J. W. (1998). Individual and collective representations in social context: a modest contribution to resuming the interrupted project of a sociocultural development psychology. Human Development, 41, 215-235.

Oliveira, P. S. (1982). Brinquedos artesanais e expressividade cultural. São Paulo: SESC-CELAZER

Sager, F., \& Sperb, T. M. (1998). O brincar e os brinquedos nos conflitos entre crianças. Psicologia: Reflexão e Crítica, 11, 309-326.

Smith, P. (1995). Play, ethology and education: a personal account. In A. D. Pellegrini (Org.), The future of play theory: a multidisciplinary inquiry into the contributions of Brian Sutton-Smith (pp. 3-21). Nova York: State University of New York Press.

Smith, P. (2004). Play: types and functions in human development. In B. J. Ellis \& D. F. Bjorklund (Orgs.), Origins of the social mind: Evolutionary Psychology and child development (pp. 271-291). Nova York: Guilford.

Striano, T., Tomasello, M., \& Rochat, P. (2001). Social and object support for early symbolic play. Developmental Science, 4, 442-455.

Sutton-Smith, B. (1986). Toys as culture. Nova York: Gardner.

Vygotsky, L. S. (1984). A formação social da mente. São Paulo: Martins Fontes.

Yumi Gosso é doutora em Psicologia Experimental pela Universidade de São Paulo. Endereço para correspondência: Rua Juréia, 356, apto.21, São Paulo, SP, CEP 04140-110, Tel. (11) 5083-1143. E-mail: ygosso@yahoo.com

Maria de Lima Salum e Morais, doutora em Psicologia Experimental pela Universidade de São Paulo, é pesquisadora científica no Instituto de Saúde (SESSP).

Emma Otta, doutora em Psicologia Experimental pela Universidade de São Paulo, é professora titular no departamento de Psicologia Experimental do Instituto de Psicologia da Universidade de São Paulo. 